\title{
Coulisses
}

Revue de théâtre

42 | Printemps 2011

Racine : Théâtre et émotion

\section{Shakespeare, Roméo et Juliette}

Mise en scène de Guillaume Dujardin au Château de Joux, août 2010

David Ball

\section{CpenEdition}

\section{Journals}

Édition électronique

URL : https://journals.openedition.org/coulisses/692

DOI : $10.4000 /$ coulisses. 692

ISSN : 2546-9460

Éditeur

Presses universitaires de Franche-Comté

\section{Édition imprimée}

Date de publication : 15 février 2011

Pagination : 105-108

ISBN : 978-2-84867-316-5

ISSN : $1150-594 \mathrm{X}$

Référence électronique

David Ball, «Shakespeare, Roméo et Juliette », Coulisses [En ligne], 42 | Printemps 2011, mis en ligne le 30 novembre 2016, consulté le 29 décembre 2022. URL : http://journals.openedition.org/coulisses/ 692 ; DOI : https://doi.org/10.4000/coulisses.692 


\section{Shakespeare, Roméo et Juliette}

Mise en scène de Guillaume Dujardin au Château de Joux août 2010

DAVID BALL

Une forteresse dont les rigueurs eurent raison de la vie et de la révolte libertaire de Toussaint L'Ouverture, fournira-t-elle un cadre convenable à la tragédie la plus célèbre des jeunes amants maudits ? Question sans réponse définitive le soir du $1^{\text {er }}$ août 2010 : temps orageux qui nécessita un repli sur le théâtre municipal de Pontarlier, où manquait cruellement l'escalier imposant de la cour du château, qui aurait fourni surtout son balcon à Juliette. La scène du théâtre était vide, entourée de rideaux noirs et, jonchées par terre, quelques branches d'arbres ne dessinaient pas vraiment le jardin bien rangé du frère Laurent et encore moins les lieux bâtis et emmurés typiques de la pièce, que les vieilles pierres du château, encore une fois, auraient beaucoup mieux suggérés.

Dans la mise en scène simple, fluide et efficace de Guillaume Dujardin, neuf jeunes acteurs assurent tous les rôles avec énergie et sincérité. Une dixième voix, plus âgée, celle du Prince, vient du fond du théâtre pour annoncer haut et fort ses jugements. Les costumes sont d'aujourd'hui, avec très peu d'accessoires. Jusqu'à la mort de Mercutio, moment fort, les acteurs semblent jouer le plus souvent à côté de leurs rôles. Ils ne sont pas aidés, il faut le dire, par la musique insistante qui accompagne la scène du banquet, une musique techno qui non seulement les rend parfois inaudibles mais qui a aussi tendance à les maintenir dans leur monde de jeunes d'aujourd'hui. Mais suivant la mort de Mercutio, bien jouée, ils se maintiennent à ce niveau plus élevé d'émotion.

Le jeu rapide de la mise en scène, sans entracte, devient un peu trop rapide dans la dernière scène, où le frère Laurent devrait entrer avant le réveil de Juliette, pour essayer de la faire sortir du caveau, en lui promettant refuge dans un couvent de bonnes sœurs. Mais ici il arrive après sa mort, ce qui fait qu'il y a à peine une minute entre la mort de Roméo et celle de Juliette. Une telle modification non seulement casse le rythme du dénouement et diminue l'émotion douce-amère du Liebestod, où l'amour ne peut plus s'exprimer que dans la 
mort, mais aussi prive Juliette d'un de ses meilleurs moments : sa libération de tout discours masculin d'autorité. Elle rejette les sages conseils du frère pour déterminer toute seule sa destinée en se suicidant.

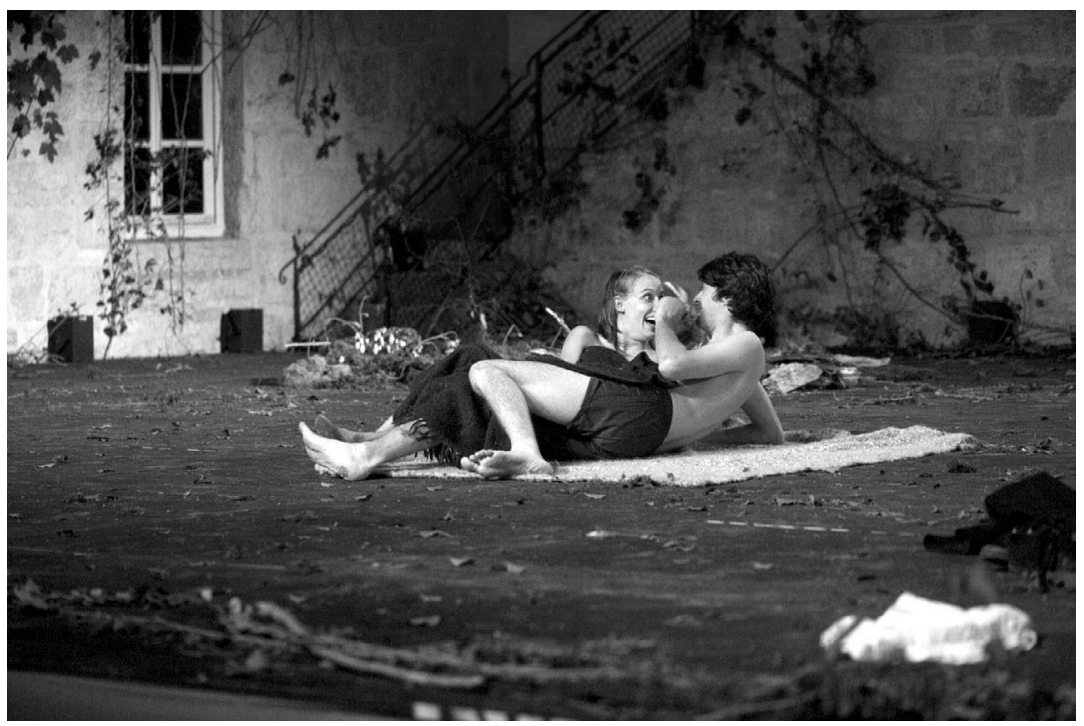

Roméo et Juliette au Château de Joux, photo : Patrice Forsans

Revenons au début: à la situation connue de tous des deux familles ennemies, celle de Roméo mortellement opposée à celle de Juliette. Les deux jeunes tombent néanmoins amoureux l'un de l'autre, et avec l'aide du frère Laurent, se marient en secret. Mais un concours de circonstances fâcheuses les amène au suicide, constat absolu de l'impossibilité de vivre l'un sans l'autre. De telles victimes de circonstances, sont-ils pourtant de vrais protagonistes de la tragédie noble ? Ne s'agit-il pas plutôt d'un drame bourgeois dont les victimes sont des naifs, des innocents? Shakespeare lui-même les présente dans son prologue comme «star-cross'd (maudits par les étoiles)». Mais l'astrologie, toujours populaire en ce qu'elle réduit notre responsabilité personnelle, n'est qu'une explication possible parmi d'autres.

De toute manière, Roméo s'en libère. En apprenant la mort présumée de Juliette, il s'écrie : «Alors, étoiles, je vous défie », avant d'acheter le poison qui mettra fin à sa vie. Il est déjà responsable de la mort de Tybalt et en partie de celle de Mercutio, et un peu plus tard, il tuera Pâris lors d'un duel, avant de se mettre aux côtés de Juliette et d'avaler son poison. Et son audace à elle ? Pour nous, une révolte parfaitement justifiée contre la tyrannie paternelle, à l'époque, 
pourtant, le bon ordre exigeait qu'une jeune fille se marie avec le consentement de son père. L'audace ne mérite pas la mort, certes, mais parfois elle la courtise. Ajoutons à cela que les fautes ou erreurs des personnages principaux ne sont pas uniquement d'ordre privé ou individuel mais touchent aux intérêts de la collectivité, qui a permis la continuation d'une dissension qui perturbe la paix et la bonne gouvernance de la cité. En termes bibliques, le héros tragique est une victime sacrificielle qui emmène avec elle dans la mort les péchés de tous pour que la paix et l'harmonie reviennent au peuple.

Peut-on aller encore plus loin dans la complication en suggérant que Roméo et Juliette est aussi une comédie joyeuse ? Une comédie de l'amour, de l'insouciance, de la joie de vivre. Une comédie qui, comme le début d'Othello, ne sert qu'à accentuer enfin la force du tragique, d'un monde cruel qui ne permet pas de tels épanouissements. Dans les premières scènes de la pièce, les propos complaisants de Roméo se plaignant sans cesse de son amour malheureux pour Rosaline sont tournés en dérision par Mercutio, comme ceux d'Orlando dans Comme il vous plaira sont moqués par Jacques le mélancolique. Et Juliette, lors de ses premières rencontres avec Roméo, joue à peu près le même rôle sceptique ou modérateur à l'égard de l'hyperbole de son amoureux que Rosalinde ou les dames de Peines d'amour perdues.

Et puis, d'une autre façon, dans Le Songe d'une nuit d'été, comédie écrite dans les mêmes années 1590 que Roméo et Juliette, Shakespeare réécrit son histoire tragique en farce. C'est la tragédie absurde de Pyrame et Thisbé jouée par les artisans devant le duc Thésée. Là aussi deux amants sont séparés par l'opposition de leurs pères, et par un mur, et meurent, lui se tuant en croyant que sa bien aimée est déjà morte, et elle ensuite en le découvrant vraiment mort. Dans la version des artisans, où le mur, le lion et le clair de lune ont tous droit à la parole, tout est du burlesque inconscient. (Voir le commentaire de Gisèle Venet dans le premier tome de la nouvelle édition de la Pléiade des Tragédies de Shakespeare, 2002, p. 1329-30 et 1340. Les citations sont aussi de cette édition. Traduction de Jean-Michel Déprats.)

Mais là où dans les comédies ce sont typiquement les voix féminines qui sont décisives et qui mènent les couples aux mariages, satisfaisants sur tous les plans, de la conclusion, ici ce sont les voix masculines qui dominent, celles, autoritaires, du père de Juliette et du frère Laurent, et celle aussi, toujours excessive et de plus en plus désespérée, de Roméo.

L'excès, oui, comme toujours dans la tragédie, mais la beauté ? Le lyrisme? Les déclarations d'amour les plus ravissantes de la langue anglaise ? Comment ne pas entendre dans les envolées lyriques des deux amants un tout autre discours que celui de leurs aînés et même de leurs contemporains? Dans Antoine et Cléopatre et dans la plupart des autres tragédies de Shakespeare, les personnages principaux se présentent le plus souvent comme des gens du passé, qui parlent d'honneur, de noblesse, de coutume, et pour qui les liens sociaux sont 
plus affectifs qu'utilitaires. Antoine la victime d'Octave ou Othello la victime d'Iago ou encore Lear et Gloucester, victimes de leurs enfants ambitieux, n'ont rien compris de l'époque nouvelle où prévalent le cynisme, l'individualisme et l'esprit pratique. Mais Roméo et Juliette ne sont pas les victimes de l'avenir mais du passé. L'avenir, ils le représentent, notre monde à nous où l'amour est libre, où il n'y a plus de séparation entre l'amour, chose poétique, et le mariage, chose pratique ; et le passé dont ils sont les victimes est celui de l'amour soumis à la haine ancestrale et au choix du père. C'est un passé, pourtant, qui refuse de disparaître, d'où l'actualité toujours évidente et nécessaire d'une pièce tout imprégnée des conventions de l'amour courtois du Moyen Âge!

C'est une pièce d'une extraordinaire richesse, mais si nous pouvions la voir un instant comme un tableau, tous ses éléments là simultanément, ce sont, je crois, ses couleurs vives qui domineraient, la fraîcheur et l'exubérance des jeunes amants, amis, acteurs, les acteurs du texte poétique réunis, comme ici, avec ceux qui les incarnent sur scène. Une scène vide leur suffira, tant le texte nous dit tout, mais la tradition exige qu'on y ajoute un balcon! 